\section{Ação afirmativa e políticas de cotas: reflexóes e críticas}

André Cicalo. Urban encounters: affirmative action and black identities in Brazil. Nova York, Palgrave/ Macmillan, 2012. 242 páginas.

\section{Myrian Sepulveda dos Santos}

Urban encounters: affirmative action and black identities in Brazil, de André Cicalo, tem como referência sua tese de doutorado sobre cotas raciais e ação afirmativa no Rio de Janeiro, defendida sob orientação de Peter Wade, professor da Universidade de Manchester (UK). Publicado pela Palgrave/ Macmillan, em 2012, e aguardando tradução e publicação no Brasil, este é um livro que intervém no debate sobre cotas universitárias e ação afirmativa de forma reflexiva, desconstruindo mitos e apontando caminhos. Diferentemente de publicações do gênero, a pesquisa em questão atrai a atenção dos leitores desde suas primeiras páginas, apesar do grande número de referências teóricas que vão dando sustentação aos argumentos defendidos ao longo do texto. Até mesmo as engrenagens metodológicas são descritas de forma a tornar o percurso acadêmico um caminho familiar a uma plateia mais ampla. André Cicalo consegue a proeza de retirar, de cifras estatísticas, pessoas de carne e osso, com seus desejos, aspiraçôes e sofrimentos. Dos entrevistados, não temos apenas seus nomes e suas falas, mas sua inserção espacial, econômica, política e cultural na cidade do Rio de Janeiro.

Em 2003, a Universidade do Estado do Rio de Janeiro (Uerj) estabeleceu pioneiramente uma política de cotas para negros e carentes, medida que se expandiu para praticamente todo o sistema universitário nos anos subsequentes. Neste livro, o autor enfrenta o debate sobre o tema, que teve seus defensores e críticos, a partir de uma pesquisa etnográfica realizada ao longo dos anos 2007 e 2008 com alunos cotistas da Uerj. Apesar de a pesquisa ter por foco um determinado grupo de estudantes, foram levantadas questôes gerais, fundamentais à compreensão de suas práticas e escolhas, como a organização de movimentos sociais vinculados à luta por reconhecimento; o protagonismo do Estado na implementação de políticas de ação afirmativas; e os conflitos entre centro e periferia, espaços da cidade em que são simbolicamente constituídas questóes de poder e subalternidade.

Como sabemos, as políticas afirmativas fazem parte de debates mais gerais entre os chamados universalistas e comunitaristas, em que filósofos e cientistas políticos discutem as questôes éticas inerentes às normas estabelecidas. Enquanto para os primeiros são priorizadas a natureza e a justificativa dos direitos individuais, para os últimos são os direitos básicos de grupos constituídos que precisam ser considerados. A questão, que retorna a cada década com novos interlocutores, e que gravita em torno do debate sobre a forma mais justa de democracia liberal, se ela deve-se apoiar nos direitos dos indivíduos ou de grupos constituídos, está bem pontuada nas consideraçōes de autores como Charles Taylor (1994), Nancy Fraser e Axel Honneth (2003).

Antes, contudo, de qualquer posicionamento sobre o tema, Cicalo propõe uma abordagem etnográfica em que procura compreender o impacto das políticas de cotas sobre um grupo de jovens que acabara de ingressar na universidade. Uma das questôes chaves a ser investigada diz respeito à possível racialização da sociedade brasileira, cujo imaginário se apresenta fortemente associado à mestiçagem e ao mito da democracia racial. Ou seja, as políticas públicas, em vez de terem por princípio a defesa aos direitos iguais para todos, estariam operando e até mesmo incentivando o fortalecimento de diferenças sociais, no caso em questão, baseadas no critério racial. Considerando os argumentos levantados tanto por defensores (Carvalho, 2005), como por opositores (Fry et al., 2007) da política de cotas, o autor parte para a análise dos diversos significados que a questão racial assumia para Flávia, Glória, Eliane, Jamerson, Gabriel, Victor e outros tantos calouros do curso de Direito da Universidade do Estado do Rio de Janeiro (Uerj).

O grupo de alunos investigado pode ser compreendido como um microcosmo da sociedade mais ampla. É interessante destacar que muitas das conclusōes do autor aparecem reiteradas nas análises quantitativas da Pesquisa das Características Étnico-raciais da População - PCERP, realizada em 2008, pelo Instituto Brasileiro de Geografia e Estatística (IBGE), ainda que na pesquisa o estado 
do Rio de Janeiro não tenha sido selecionado. $\mathrm{O}$ estudo da declaração de cor ou raça através de questionários que consideram a autoclassificação da população mostra a complexidade inerente às classificações étnico-raciais. ${ }^{1}$

A Faculdade de Direito da Uerj, por ser uma das melhores em sua área no estado do Rio de Janeiro, é procurada por setores mais favorecidos da população. Tradicionalmente, preenchiam as vagas deste curso, como também era o caso em outros cursos, como o de medicina e o de desenho industrial, alunos oriundos de escolas particulares, moradores da zona sul e com maior acesso a recursos de toda sorte. As contradições e os conflitos entre estes alunos e aqueles que ingressam por cotas, em sua grande maioria, oriundos de bairros mais pobres, são descritas minuciosamente. Há uma divisão entre os alunos que é marcada até mesmo pela ocupação da sala de aula, pois, enquanto os primeiros ocupam as cadeiras localizadas no final da sala, ostentando uma atitude mais despreocupada em relação ao ensino, os cotistas ocupam as primeiras filas, ansiosos por responder com êxito as novas demandas. Enquanto a universidade é vista por uns como uma extensão natural de sua vida acadêmica, para outros ela surge como conquista, desejo e desafio.

Os grupos se formam não só de acordo com aspectos materiais, como poder aquisitivo, vestimentas, locais de moradia e transportes utilizados, mas também devido a elementos menos visíveis, como comportamentos cotidianos, formas de falar, ambiente familiar, opções de lazer, noçōes estéticas, sentimentos de pertença e de exclusão e desejos. Aspectos físicos, incluindo cor de pele e traços fisionômicos e corporais estão associados aos demais. Muitas dessas marcas operam de forma estigmatizante. Uma das entrevistadas expressa o impacto dessas barreiras, algumas visíveis, outras não, sobre si mesma, ao "confessar" que os pobres têm vergonha de sua própria condição. Os alunos cotistas dizem identificar seus pares pelo seu perfil humilde, pele mais escura e sentimento de estarem "fora do lugar". Entre eles, Cicalo destaca o consenso sobre a máxima de que "o estudante branco pode ser cotista, mas não parece, enquanto o estudante negro pode não ser, mas parece".
Apesar de acompanharmos uma descrição minuciosa dos diversos itens que levam às classificações constituídas, o autor é bem atento à porosidade existente nesses processos, uma vez que a diversidade entre alunos faz com que muitos deles, apesar de identificados com um grupo, não se adéquem ao lugar atribuído. Como seria de esperar, nem todos são ricos, nem todos são pobres, nem todos são brancos e nem todos são negros. Aqueles que chegam à universidade por cotas já têm o nível médio completo, o que implica que tiveram certo suporte familiar ou social. Por sua vez, a opção dos não-cotistas por uma universidade pública pode estar associada aos altos custos do ensino privado.

No que diz respeito ao item cor/raça, às diferenças sociais, ou mesmo à política de cotas, uma questão que se destaca entre os calouros é o silêncio. A defesa da meritocracia algumas vezes surge nas conversas e emudece o debate entre os alunos, tornando embaraçosa a presença dos cotistas, apesar de levantamentos estatísticos mostrarem reiteradamente que estes alcançam ao longo do curso desempenho igual ou superior aos não-cotistas.

A política de cotas da Uerj favorece alunos oriundos de escolas públicas e negros e são geralmente estes estudantes que quebram o silêncio e fazem referência, apenas entre eles próprios, ainda que de forma irônica, tanto à existência do preconceito racial, como aos lugares precarizados que eles ocupam na sociedade. $\mathrm{O}$ não-dito surge como resultado de um pacto em que as partes evitam o conflito aberto, reiterando desigualdades e hierarquias. Essa harmonia que mantém hierarquias e se apoia no não dito, como sabemos, não faz parte apenas das classes de Direito da Uerj. No caso específico da sala de aula, podemos ainda nos perguntar em que medida esse convívio ameaça privilégios? Embora desejado como uma forma de escape à pobreza, os diplomas universitários são apenas um dos itens a serem considerados na obtenção de bons empregos. Em diversas profissões, conhecimentos e indicações familiares são bem mais importantes do que currículo acadêmico.

Reiterando o que autores como Sansone (2003) e Telles (2004) já haviam observado sobre a flexibilidade entre discursos sobre mestiçagem e negritude, Cicalo enfatiza que seus entrevistados 
podem se identificar como pardos ou como negros, dependendo da situação. Além disso, observa que tanto cotistas oriundos de escolas públicas como aqueles que se classificaram como negros se identificam de acordo com múltiplos fatores. Um jovem pode se identificar simultaneamente como pardo e negro, sendo que uma classificação se associa à cor e à aparência e outra à origem. A negritude é compreendida por muitos como parte da ancestralidade e da necessidade de reparação a injustiças e preconceitos, mas não exclui outros tipos de identificação. Em alguns casos, critérios de cor e raça são especificados, mas nem sempre isso acontece. Para esses alunos, a adesão ao sistema de cotas não é resultado necessariamente da classificação entre brancos e negros, uma vez que discursos sobre mestiçagem permanecem ativos.

Embora pouco tratada em estudos sobre conflitos étnicos e raciais, a simultaneidade de crenças, valores e práticas, que pertencem a correntes de pensamento muitas vezes em oposição, vem sendo bem trabalhada entre aqueles que tem por objeto a memória coletiva. Além disso, podemos compreender que indivíduos tanto refazem imaginários sociais herdados, de acordo com novas necessidades, conflitos e pressões sociais, como os reproduzem de forma quase automática. As ideias relacionadas com a supremacia da raça branca, a democracia racial e mesmo com as novas identidades negras ou afrodescendentes, que foram constituídas nos últimos séculos, não podem ser dispostas em forma linear; muito pelo contrário, elas formam um mosaico em que significados são ambíguos e contrários coexistem (Santos, 2013, p. 160).

Uma das principais críticas ao sistema de cotas universitárias diz respeito à reificação de identidades a partir de uma política pública que reforça o sistema birracial, importado dos Estados Unidos, em um país em que a grande maioria da população não se identifica racialmente, mas a partir de inúmeros elementos. Sobre a tendência apontada por alguns autores de haver uma bipolarização crescente no âmbito das relações raciais no Brasil (Hanchard, 1999; Sansone, 2003; Telles, 2004), Cicalo traz à tona algumas observações importantes. Segundo ele, é preciso não superdimensionar essa tendência, uma vez que seus informantes mostraram que eles continuam a operar com uma multiplicidade de fatores em sua identificação. Ao acompanhar as mudanças apresentadas por uma das calouras ao longo do curso, o autor reconhece sua politização a partir do encontro com grupos organizados do movimento negro, como o Educafro, uma rede de pré-vestibulares comunitários voltados para a inclusão da população negra nas universidades públicas, e o DeNegrir, coletivo de estudantes negros da Uerj. Inegavelmente, o ambiente universitário propicia uma maior reflexão e crítica por parte dos alunos, que procuram tornar seus discursos mais coerentes e críticos. Este processo, contudo, é lento e não tem uma única direção. Apesar de não fazer parte do trabalho de campo de Cicalo, ocorrido três anos antes, vale lembrar que em 2013 um grupo de estudantes negras organizou a "revolução dos turbantes", participando de manifestações públicas e denunciando o coletivo DeNegrir como "homofóbico, lesbofóbico, sexista e machista". ${ }^{2}$

Apesar das barreiras constituídas, o que os diversos exemplos trazidos de convivência entre cotistas e não-cotistas dizem ao autor é que o convívio não apaga as marcas que cada grupo traz para a sala de aula, mas também não acirra as diferenças. Sua pesquisa sugere que a implementação do sistema de cotas na Uerj, longe de provocar tensões raciais e ressentimento, produziu no grupo de calouros um ambiente favorável a encontros urbanos e tornou efetiva a inclusão de estudantes que rompiam com o horizonte anterior de vida, presente no círculo familiar e até mesmo em suas comunidades de origem. Esses estudantes participavam pela primeira vez da vida universitária. Os não-cotistas, por sua vez, incorporaram a diversidade social e racial à identidade de seus cursos universitários, mostrando orgulho de fazerem parte do coletivo. Contudo, longe de se ater apenas aos aspectos positivos das políticas de cotas, Cicalo conclui seu estudo com uma série de importantes questionamentos, desde a incapacidade do Estado em prover ensino público gratuito de boa qualidade para todos, passando pelas dificuldades daqueles identificados como mais negros de ascenderem socialmente, embora no contexto de políticas afirmativas, e chegando à proposta de criação de "tribunais raciais" responsáveis pela identificação e seleção de candidatos. 


\section{Notas}

1 Para percentuais sobre percepção de cor ou raça a partir das catorze categorias mais frequentes, multiplicidade de dimensões definidoras das categorias de cor e raça, proximidade entre auto e heteroclassificação, e outros temas, ver a coletânea de artigos organizada por Petruccelli e Saboia (2013).

2 Disponível em https://banhodeassento.wordpress. com/2013/07/13/carta-aberta-de-repudio-ao-coletivo-de-estudantes-negros-e-negras-da-uerj-denegrir/, consultado em 3 de fevereiro de 2015.

\section{BIBLIOGRAFIA}

CARVALHO, José Jorge. (2005), Inclusão étnica e racial no Brasil: a questão das cotas no ensino superior. São Paulo, Attar.

FRASER, Nancy \& Honneth, Axel (eds.). (2003), Redistribution or recognition? A political-philosophical exchange. Londres/Nova York, Verso.

FRY, Peter; MAGGIE, Yvonne; CHOR MAIO, Marcos; Monteiro, Simone \& VENTURA, Ricardo (eds.). (2007), Divisóes perigosas: políticas raciais no Brasil contemporâneo. Rio de Janeiro, Civilização Brasileira.

TAYLOR, Charles. (1994), "The politics of recognition”, in Amy Gutmann e Taylor Charles (eds.), Multiculturalismo: examining the politics of recognition, Princeton, NJ, Princeton University Press.

HANCHARD, Michael (ed.). (1999), Racial politics in contemporary Brazil. Durham, Duke University Press.

PETRUCCELLI, José Luis \& SABOIA, Ana Lucia (orgs.). (2013), Características étnico-raciais da população: classificação e identidades. Rio de Janeiro, IBGE (série Estudos e Análises. Informação Demográfica e Socioeconômica, 2).

SANSONE, Livio. (2003), Blackness without ethnicity: constructing race in Brazil. Nova York, Palgrave Macmillan.

SANTOS, Myrian Sepúlveda. (2013), Memória coletiva e identidade nacional. São Paulo, Annablume.

TELLES, Edward. (2004), Race in another America: the significance of skin color in Brazil. Princeton, NJ, Princeton University Press.
MYRIAN SEPULVEDA DOS SANTOS

é professora associada do Instituto de Ciências Sociais da Universidade do Estado do Rio de Janeiro. Coordena o grupo de pesquisa Arte, Cultura e Poder (www.artecultpoder.org) e faz parte da coordenação colegiada do Museu Afrodogital Rio (www.museuafrodigitalrio.org). E-mail: myrian.sepulveda.santos@gmail.com.

DOI: http//dx.doi.org/10.17666/3088181-184/2015 